\title{
Robust kestirim yöntemlerinin deformasyon analizinde uygulanmasında farklı yaklaşımların güvenilirliğinin araştırılması
}

\author{
Bahattin Erdoğan ${ }^{1 *}$ (D), Gülşah Mandalinci ${ }^{1}$ (iD \\ ${ }^{1}$ Yıldız Teknik Üniversitesi, Davutpaşa Kampüsü, Inşaat Fakültesi, Harita Mühendisliği Bölümü, Esenler, İstanbul.
}

\begin{abstract}
Öz: Deformasyon analizi Harita Mühendisliği uygulamalarında önemli konulardan biridir. Klasik anlamda deformasyon analizi, farklı ölçüm periyotlarındaki koordinat farklarının karşılaştııllması esasına dayanır. Koordinat farklarının istatistiksel olarak anlamlı olduğu ispatlanırsa, nokta koordinat değişimleri yer değiştirme olarak yorumlanır. Klasik deformasyon analiz (KDA) modellerinin yanı sıra, benzerlik (Helmert) dönüşümü de deformasyon analizinde kullanılan yöntemlerden biridir. Benzerlik dönüşümünde, dönüşüm işlemi sonucunda ortaya çıkacak düzeltme değerleri deformasyon analizinde kullanılabilir. Hem klasik hem de robust yöntemlerle elde edilen düzeltme değerleri incelenerek noktaların yer değiştirip değiş̧tirmediği belirlenebilir. Deformasyon analiz yöntemleri her durumda doğru ve aynı sonuçları vermez. Yöntemlerin başarıları kullanılan veri setine, ağdaki yer değiştirmiş nokta sayısına ve yer değiștirmenin büyüklüğ̈̈ne göre değişir. Analiz yöntemlerinin güvenilirliğini ölçmek için kullanılan yöntemlerden bir tanesi de Ortalama Başarı Oranı $(O B O)$ kavramıdır. Bu çalışmada, yatay bir kontrol ağı iki periyot olarak simüle edilmiştir. Birinci periyot ölçülerinde sadece rastgele hatalar, ikinci periyot ölçülerinde ise hem rastgele hatalar hem de yer değiştirme büyüklükleri dikkate alınmıştır. Her iki periyot ölçüleri bir örnek kümeyi oluşturmaktadır. Bu örnek kümelerde iki farklı yaklaşımla robust yöntemlerin deformasyon analizinde kullanılabilirliği araştırılmıştır. Birinci yaklaşımda, benzerlik dönüşümünde robust kestirim yöntemlerinden elde edilen düzeltme değerlerine anlamlılık testi uygulanarak deformasyona uğramış noktalar belirlenmiştir. İkinci yaklaşımda ise, aynı düzeltme değerleri kullanılarak uyuşumsuz ölçü belirleme stratejisi ile deformasyona uğrayan noktalar belirlenmeye çalışılmıştır. Çalışmada 10000 farklı örnek küme kullanılmıştır. Her iki yaklaşım da KDA sonuçları ile karşılaştırılmıştır. Elde edilen sonuçlara göre yer değiştiren bir nokta için KDA yöntemi ve robust yöntemler benzer sonuçlar verse de; ağda birden fazla yer değiş̧tiren nokta olması durumunda KDA yönteminin daha başarılı sonuçlara sahip olduğu görülmüştür. Ayrıca, ağda yer değiştiren nokta sayısı arttıkça yöntemlerin sonuçlarının OBO değerleri düşmektedir. Buna karşın, yer değiştirme büyüklükleri arttıkça OBO değerleri de artmaktadır.
\end{abstract}

Anahtar Sözcükler: Benzerlik dönüşümü, Deformasyon analizi, Güvenilirlik, Robust yöntemler

\section{Investigation of the reliability of the different approaches for using the robust estimation methods in deformation analysis}

Abstract: Deformation analysis is one of the most important subjects in Geomatic Engineering. It classically depends on the comparison of the coordinates' differences estimated in different periods. If the coordinate differences are statistically proved as significant, they are interpreted as displacement. In literature there are different deformation analysis models. As well as conventional deformation analysis (CDA) models, similarity (Helmert) transformation is one of these models used for deformation analysis. In similarity transformation, the residuals to be estimated from similarity transformation can be used in deformation analysis. By investigating the residuals estimated from both conventional and robust methods, it can be determined whether the point has displaced or not. Deformation analysis methods do not provide correct and the same results in all conditions. The successes of the methods change depending on the sample dataset used, the number of the displaced points in the network and the magnitude of the displacement. One of the methods used for measuring the reliability of the analysis methods is the Mean Success Rate (MSR). In this study, a horizontal control network has been simulated as two periods. Since only the random errors are considered in the first period measurements, for the second period measurements, both random errors and magnitudes of the displacements are taken into consideration. Each of these periods forms one working sample. The usability of the robust methods in deformation analysis for two different approaches has been investigated by using this working samples. In the first approach, the displaced points have been identified by applying the significance test to the residuals estimated by robust methods in similarity transformation. In the second approach, the displaced points have been detected by applying the outlier detection strategy to the same residuals. In this study, 10000 working samples have been formed. The results of both approaches have been compared with the results of the CDA methods. According to the results obtained, although both CDA and robust methods have similar results for one displaced point, in the case of more than one displaced point CDA has more reliable results than robust methods. Also, when the number of the displaced points increase, the MSRs of the methods decrease. Contrary to this, if the magnitudes of the displacements increase, the MSRs of the methods increase.

Keywords: Similarity transformation, Deformation analysis, Reliability, Robust methods

* Sorumlu Yazar/Corresponding Author: Tel: +90 2123835291

0000-0002-8060-9208, berdogan@yildiz.edu.tr (Erdoğan B.)* 0000-0003-4773-3386, gulsahmandalinci@gmail.com (Mandalinci G.)
Geliş Tarihi/Received: Kabul Tarihi/Accepted:

07.01 .2019 24.04.2019 


\section{Giriş}

Klasik anlamda jeodezik deformasyon ölçmeleri, çalışma alanı içerisinde ilgilenilen objeyi ve çevresini en uygun şekilde geometrik olarak modelleyerek, bölgede meydana gelen deformasyonu belirlemeyi amaçlar (Welsch \& Heunecke, 2001). Başka bir deyişle, klasik jeodezik deformasyon ölçmelerinin amacı, araştırma bölgesinin davranışlarını modellemek, araştırma konusunu temsil eden geometrik bir model oluşturmak, modelin çevresine göre yatay konum ve yükseklik değişimlerini belirlemek ve oluşan şekil değişikliklerini zamanın bir fonksiyonu olarak elde etmektir (Öztürk, Konak \& Atasoy, 2006).

Jeodezik deformasyon analizi, jeodezik ağların tasarımı, kurulması, ölçülmesi, farklı zamanlarda elde edilen ölçülerin En Küçük Kareler (EKK) yöntemine göre dengelenmesi ve sonuçların analiz edilmesi adımlarından oluşur. Yeni teknolojilerin ve ölçüm tekniklerinin geliştirilmesi ile birçok deformasyon modeli; statik, kinematik, dinamik, gerinim vb. çalışmalarda kullanılmaktadır.

Jeodezik ölçülerin değerlendirilmesinde yaygın olarak kullanılan EKK yöntemi, ölçüler normal dağılımlı olduğunda ve ölçü kümesinde uyuşumsuz ölçü bulunmadığında en iyi, en uygun kestiricidir. Ancak ölçülerde uyuşumsuz ölçüler varsa, bunlar EKK yönteminden elde edilecek parametreleri olumsuz etkilemektedir. Özellikle EKK kestiriminin yayıcı etkisi ve test istatistiğinin yetersizliği nedeniyle her durumda doğru sonuçlar elde edilememektedir. Bu nedenle EKK yöntemine dayalı uyuşumsuz ölçü testleri yanında robust yöntemler de geliştirilmiştir (Baarda, 1968; Pope, 1976; Huber, 1981; Hampel, Ronchetti, Rousseeuw \& Stahel, 1986; Rousseeuw \& Leroy, 1987; Hekimoğlu \& Berber, 2003; Hekimoğlu, 2005; Hekimoğlu \& Erenoğlu, 2007; Yu, Shen, Yang \& Nie, 2017). Deformasyon analizinde de benzer sorunlarla karşılaşılmaktadır. EKK yönteminin modeldeki bozucu etkiyi yayması sonucunda periyotlar arasındaki yer değiştirmeler dengeleme sonuçlarına tam olarak yansımamakta ve analiz sonuçlarının güvenilirliği beklenenden düşük çıkmaktadır (Hekimoğlu, Erdoğan \& Butterworth, 2010). Bu nedenle kestirici olarak robust yöntemler kullanılarak daha güvenilir sonuçlar elde edilmek istenmektedir (Duchnowski \& Wiśniewski, 2014; Nowel \& Kamiński, 2014; Nowel, 2016; Wiśniewski \& Zienkiewicz, 2016; Zienkiewicz, Hejbudzka \& Dumalski, 2017).

Bu çalışmanın amacı, yüksek doğruluk gerektiren jeodezik deformasyon analizinde robust kestirim yöntemlerini kullanarak elde edilen sonuçların güvenilirliğini araştırmaktır. Bu bağlamda robust yöntemlerin deformasyon analizinde uygulanması için iki farklı yaklaşım kullanılmıştır. Yatay bir kontrol ağı iki periyot olarak simüle edilmiştir. Her iki periyot çiftinden 10 000 adet farklı örnek küme oluşturulmuştur. Simülasyonla elde edilen yatay kontrol ağında robust M-kestirici olarak Huber, Danimarka, Hampel, Andrews, Beaton ve Tukey yöntemleri kullanılmış ve elde edilen sonuçlar klasik deformasyon analiz (KDA) sonuçları ile karşılaştırılmıştır. Çalışmanın ikinci bölümünde KDA'dan, üçüncü bölümünde ise çalışmada kullanılan robust yöntemlerden bahsedilmektedir. Dördüncü bölüm ise gerçekleştirilen simülasyon çalışmasını içermektedir. Beşinci bölümde de elde edilen sonuçlar verilmektedir.

\section{Klasik Deformasyon Analizi}

KDA zamana bağlı olarak obje şeklinin ve yer değiştirmelerinin incelenmesidir. Tektonik hareketlerin modellenmesi veya mühendislik yapılarındaki deformasyonların izlenmesinde kullanılan modeller, analizlerde dikkate alınan parametrelere (geometrik değişim, hız, ivme, kuvvet vb.) göre değişiklik göstermektedir. Bu çalışmada sadece objedeki geometrik değişimlerin incelendiği KDA yöntemi uygulanmıştır. 


\subsection{Global Uyumluluk Testi}

KDA'da öncelikle ölçüm periyotları arasında herhangi bir yer değiştirme olup olmadığı global uyumluluk testi ile araştırılır. Global uyumluluk testi, iki farklı ölçüm periyodu için bölgeyi temsil eden noktalar arasında anlamlı konum değişimi olup olmadığını belirler. Bu amaçla, her iki periyoda ilişkin eşlenik nokta koordinatlarının beklenen değerlerinin birbirine eşit olduğu sifir hipotezi öngörülür:

$H_{0}:\left[\begin{array}{ll}-\mathbf{I} & \mathbf{I}\end{array}\right]\left[\begin{array}{l}E\left(\hat{\mathbf{x}}_{\mathbf{1}}\right) \\ E\left(\hat{\mathbf{x}}_{2}\right)\end{array}\right]=\mathbf{0}$

$H_{1}:\left[\begin{array}{ll}-\mathbf{I} & \mathbf{I}\end{array}\right]\left[\begin{array}{l}E\left(\hat{\mathbf{x}}_{\mathbf{1}}\right) \\ E\left(\hat{\mathbf{x}}_{2}\right)\end{array}\right] \neq \mathbf{0}$

Burada E() beklenen değeri, $\widehat{\mathbf{x}}_{\mathbf{1}}$ ve $\widehat{\mathbf{x}}_{\mathbf{2}}$ srrasıyla birinci ve ikinci periyotlar için kestirilen bilinmeyenler vektörünü ifade etmektedir. Her iki ölçüm periyodu için ağlar ayrı ayrı serbest dengelenirse, dengeleme sonuçları

$\hat{\mathbf{x}}_{1}=\mathbf{Q}_{\widehat{\mathbf{x}} 1 \hat{\mathbf{x}} \mathbf{1}} \mathbf{A}_{1}^{\mathrm{T}} \mathbf{P}_{1} \mathbf{l}_{1}, \mathbf{Q}_{\hat{\mathbf{x}} 1 \hat{\mathbf{x}} \mathbf{1}}=\mathbf{N}_{11}^{+}=\left(\mathbf{A}_{1}^{\mathrm{T}} \mathbf{P}_{1} \mathbf{A}_{1}\right)^{+}$

$\widehat{\mathbf{x}}_{2}=\mathbf{Q}_{\hat{\mathbf{x}} 2 \hat{\mathbf{x}} 2} \mathbf{A}_{2}^{\mathrm{T}} \mathbf{P}_{2} \mathbf{l}_{2}, \mathbf{Q}_{\hat{\mathbf{x}} 2 \hat{\mathbf{x}} 2}=\mathbf{N}_{22}^{+}=\left(\mathbf{A}_{2}^{\mathrm{T}} \mathbf{P}_{2} \mathbf{A}_{2}\right)^{+}$

şeklinde hesaplanır. Her iki periyotta hesaplanan varyans değerlerinin uyumlu olup olmadığı test edildikten sonra, ortak varyans değeri (4) ve (5) eşitlikleri ile elde edilir.

$\Omega=\mathbf{v}_{1}^{\mathrm{T}} \mathbf{P}_{1} \mathbf{v}_{\mathbf{1}}+\mathbf{v}_{2}^{\mathrm{T}} \mathbf{P}_{\mathbf{2}} \mathbf{v}_{\mathbf{2}}$

$s_{0}^{2}=\frac{\Omega}{f}, f=f_{1}+f_{2}$

Burada, $\mathbf{A}_{\mathbf{1}}$ ve $\mathbf{A}_{\mathbf{2}}$ birinci ve ikinci periyot için düzeltme denklemleri katsayılar matrisini, $\mathbf{l}_{\mathbf{1}}$ ve $\mathbf{l}_{\mathbf{2}}$ birinci ve ikinci periyot için küçültüllmüş düzeltme denklemleri ölçüler vektörünü, $\mathbf{v}_{1}$ ve $\mathbf{v}_{\mathbf{2}}$ her iki periyot için ölçülere getirilecek düzeltmeler vektörünü, $\mathbf{P}_{1}$ ve $\mathbf{P}_{2}$ birinci ve ikinci periyot ölçülerinin ağırlık matrisini, $\mathbf{Q}_{\hat{\mathbf{x}} 1 \hat{\mathbf{x}} \mathbf{1}}$ ve $\mathbf{Q}_{\hat{\mathbf{x}} \mathbf{2} \hat{\mathbf{x}}}$ matrisleri birinci ve ikinci periyot için bilinmeyenlerin ağıllık katsayıları matrisini ifade etmektedir. (1) eşitliğindeki sıfır hipotezi dikkate alındığında iki periyot arasındaki koordinat farkları $(\mathbf{d})$ ve bunlara ilişkin ağılık katsayıları matrisi $\left(\mathbf{Q}_{\mathbf{d d}}\right)$,

$\mathbf{d}=\hat{\mathbf{x}}_{2}-\hat{\mathbf{x}}_{1}$

$\mathbf{Q}_{\mathrm{dd}}=\mathbf{Q}_{\hat{\mathbf{x}} 1 \hat{\mathbf{x}} 1}+\mathbf{Q}_{\hat{\mathbf{x}} 2 \hat{\mathbf{x}} 2}$

şeklinde ifade edilir. Sıfır hipotezinin dengeleme modeli üzerindeki etkisi,

$R=\mathbf{d}^{\mathrm{T}} \mathbf{Q}_{\mathrm{dd}}^{+} \mathbf{d}$

şeklinde hesaplanır. A $\breve{g}$ geometrisinin ve datum parametrelerinin her iki ölçme periyodunda da aynı kaldığı durumlarda, $u$ ağdaki koordinat bilinmeyenlerinin sayısı, $d$ datum defekt sayısı ve $R$ büyüklüğünün serbestlik derecesi $h$ olmak üzere,

$h=\operatorname{rank}\left(\mathbf{Q}_{\hat{\mathbf{x}} 1 \hat{\mathbf{x}} \mathbf{1}}\right)=\operatorname{rank}\left(\mathbf{Q}_{\hat{\mathbf{x}} 2 \hat{\mathbf{x}} 2}\right)=u-d$ 
1971; Koch, 1999).

$T=\frac{R}{s_{0}^{2} h}=\frac{\mathbf{d}^{\mathbf{T}} \mathbf{Q}_{\mathbf{d d}}^{+} \mathbf{d}}{s_{0}^{2} h}$

Uygulamada genellikle noktaların zarar görmesi veya ağın yeni noktalarla genişletilmesi sonucunda ikinci periyotta ağ geometrisi değişebilir. Deformasyon analizi her iki periyotta bulunan eşlenik noktalar için gerçekleştirilir, fakat ağdaki tüm noktalar ağ geometrisini etkilediğinden dolayı ortak olmayan noktalar da dişlanamaz. Eşlenik olmayan noktalar bir blok içinde düşünülerek dengeleme modelinden indirgeme ile yok edilebilir. Bu işlem ortak noktalara ilişkin kısmi iz minimum çözümüyle eşdeğerdir (Niemeier, 1985).

Her iki periyotta da eşlenik olup, datum tanımına giren noktalara ilişkin bilinmeyenler vektörü ve bunlara karşılık ağırlık katsayılar1 matrisi, sırasıyla $\hat{\mathbf{x}}_{\mathbf{D} 1}, \hat{\mathbf{x}}_{\mathbf{D} 2}$ ve $\mathbf{Q}_{\mathbf{D D} 1}, \mathbf{Q}_{\mathbf{D D} 2}$ olsun. Ağın eşlenik noktalar bölümünde global uyumluluk testini uygulamak için, her iki periyot aynı datumda kısmi iz minimum çözümüne göre serbest olarak dengelenir. Koordinat farkları ve ilgili ağırlık katsayıları matrisi,

$\mathbf{d}_{\mathbf{D}}=\hat{\mathbf{x}}_{\mathbf{D} 2}-\hat{\mathbf{x}}_{\mathbf{D} 1}$

$\mathbf{Q}_{\mathrm{dd}_{\mathrm{D}}}=\mathbf{Q}_{\mathrm{DD} 1}+\mathbf{Q}_{\mathrm{DD} 2}$

olur. Sifir hipotezinin etkisi ve serbestlik derecesi (13) ve (14) ile verilir:

$R_{D}=\mathbf{d}_{\mathbf{D}}^{\mathbf{T}} \mathbf{Q}_{\mathrm{DD}}^{\mathbf{T}} \mathbf{d}_{\mathbf{D}}$

$h_{D}=u_{D}-d$

Burada $u_{D}$ eşlenik noktalara ait bilinmeyen sayısını ifade etmektedir. Test büyüklüğü,

$T=\frac{R_{D}}{s_{0}^{2} h_{D}}$

ile hesaplanır. Test büyüklüğü, tüm noktalar eşlenik olduğu durumda $F_{h, f, 1-\alpha}$ güven sınırından (sadece ağın bir bölümündeki noktalar eşlenik olduğu durumda $\left.F_{h_{D}, f, 1-\alpha}\right)$ küçükse, iki periyot arasındaki nokta koordinat farklarının anlamsız olduğuna karar verilir. Aksi durumda ağda deformasyon olduğuna karar verilir ve hangi nokta veya noktalarda anlamlı konum değişimi olduğunun belirlenmesi adımına geçilir.

\subsection{S - Dönüşümü Yöntemi ile Yerelleştirme}

S - Dönüşümü yöntemi ile yerelleştirme KDA'da en çok tercih edilen yöntemlerden bir tanesidir (Niemeier, 1985; Demirel, 1987). Ağdaki tüm noktaların obje noktası olarak düşünüldüğü modeldir. Eşlenik noktalardan herhangi birinin yer değiştirmiş olabileceği göz önünde bulundurularak yerelleştirme işlemi gerçekleştirilmektedir. Her iki periyotta da serbest dengeleme ile elde edilen bilinmeyenler vektörü ve ağırlık katsayıları matrisi uygun biçimde alt vektör ve matrislere ayrılır:

$\hat{\mathbf{x}}=\left[\begin{array}{l}\hat{\mathbf{X}}_{\mathbf{F}} \\ \hat{\mathbf{x}}_{\mathbf{B}} \\ \hat{\mathbf{x}}_{\mathbf{N}}\end{array}\right]$ 
$\mathbf{Q}_{\hat{x} \hat{x}}=\left[\begin{array}{lll}\mathbf{Q}_{\mathrm{FF}} & \mathbf{Q}_{\mathrm{FB}} & \mathbf{Q}_{\mathrm{FN}} \\ \mathbf{Q}_{\mathrm{BF}} & \mathbf{Q}_{\mathrm{BB}} & \mathbf{Q}_{\mathrm{BN}} \\ \mathbf{Q}_{\mathrm{NF}} & \mathbf{Q}_{\mathrm{NB}} & \mathbf{Q}_{\mathrm{NN}}\end{array}\right]$

Burada, $\hat{\mathbf{x}}_{\mathbf{B}}$ incelenen eşlenik noktanın koordinatlarını, $\hat{\mathbf{x}}_{\mathbf{F}}$ diğer eşlenik noktaların koordinatlarını, $\hat{\mathbf{x}}_{\mathbf{N}}$ eşlenik olmayan nokta koordinatlarını, $\mathbf{Q}_{\mathbf{B B}}$ incelenen noktanın ağırlık katsayıları matrisini, $\mathbf{Q}_{\mathbf{F F}}$ diğger eşlenik noktaların ağırlık katsayıları matrisini ve $\mathbf{Q}_{\mathbf{N N}}$ eşlenik olmayan noktaların ağırlık katsayıları matrisini ifade etmektedir. A ğdaki eşlenik nokta sayısı kadar, her defasında bir nokta datum tanımından çıkarılarak geriye kalan eşlenik noktalara göre yeni bir datum tanımlanır. Her iki periyot için bilinmeyenler ve bilinmeyenlere ait kofaktör matrisi S - Dönüşümü kullanılarak yeni tanımlanan datuma dönüştürülür:

$S_{j}=\mathbf{I}-\mathbf{G}\left(\mathbf{B}_{\mathbf{j}}^{\mathrm{T}} \mathbf{G}\right)^{-1} \mathbf{B}_{\mathbf{j}}^{\mathrm{T}}$

$\mathbf{B}_{\mathbf{j}}^{\mathbf{T}}=\mathbf{G}^{\mathbf{T}} \mathbf{E}_{\mathbf{j}}$

Burada, $\mathbf{E}_{\mathbf{j}}$ bir köşegen matristir. İncelenen $j$. eşlenik noktaya ait $(\mathrm{E})_{\mathrm{jj}}$ köşegen elemanı yerine 0 , diğer eşlenik noktalara karşılık gelen köşegen elemanı için 1 alınır (Niemeier, 1985).

Bir boyutlu ağlar için $\mathbf{G}^{\mathbf{T}}$ matrisi,

$\mathbf{G}^{\mathbf{T}}=\frac{1}{\sqrt{p}}\left[\begin{array}{lllll}1 & 1 & 1 & \ldots & 1\end{array}\right]$

iki boyutlu ağlar için $\mathbf{G}^{\mathbf{T}}$ matrisi,

$\mathbf{G}^{\mathbf{T}}=\left[\begin{array}{ccccccc}1 / \sqrt{p} & 0 & 1 / \sqrt{p} & 0 & \ldots & 1 / \sqrt{p} & 0 \\ 0 & 1 / \sqrt{p} & 0 & 1 / \sqrt{p} & \ldots & 0 & 1 / \sqrt{p} \\ -y_{10}^{\prime} & x_{10}^{\prime} & -y_{20}^{\prime} & x_{20}^{\prime} & \ldots & -y_{p 0}^{\prime} & x_{p 0}^{\prime} \\ x_{10}^{\prime} & y_{10}^{\prime} & x_{20}^{\prime} & y_{20}^{\prime} & \ldots & x_{p 0}^{\prime} & y_{p 0}^{\prime}\end{array}\right]$

denklemleriyle tanımlanır.

$x_{i 0}^{\prime}=\frac{x_{i 0}-x_{s}}{\sqrt{\left[\left(x_{i 0}-x_{S}\right)^{2}+\left(y_{i 0}-y_{S}\right)^{2}\right]}}, y_{i 0}^{\prime}=\frac{y_{i 0}-y_{s}}{\sqrt{\left[\left(x_{i 0}-x_{S}\right)^{2}+\left(y_{i 0}-y_{S}\right)^{2}\right]}}, x_{s}=\left[x_{0}\right] / p, y_{s}=\left[y_{0}\right] / p, i=1,2, \ldots, p$

Burada, p ağdaki nokta sayısı, $x_{s}$ ve $y_{s}$ ağın ağırlık merkezinin koordinatlarıdır.

GPS ağlarında baz vektörleri ile gerçekleştirilen dengelemede $\mathbf{G}^{\mathbf{T}}$ matrisi,

$\mathbf{G}^{\mathbf{T}}=1 / \sqrt{p}\left[\begin{array}{ccccccc}1 & 0 & 0 & \ldots & 1 & 0 & 0 \\ 0 & 1 & 0 & \ldots & 0 & 1 & 0 \\ 0 & 0 & 1 & \ldots & 0 & 0 & 1\end{array}\right]$

biçimindedir. S - Dönüşümü ile tüm eşlenik noktaların katıldığı datumdan, yer değiştirdiği düşünülen bir eşlenik noktanın datum tanımından çıkarıldığı $j$. datuma dönüşüm yapılmaktadır.

$\left[\begin{array}{l}\hat{\mathbf{x}}_{\mathbf{F}}^{\mathbf{j}} \\ \hat{\mathbf{x}}_{\mathbf{B}}^{\mathbf{j}} \\ \hat{\mathbf{x}}_{\mathbf{N}}^{\mathbf{j}}\end{array}\right]=\mathbf{S}_{\mathbf{j}}\left[\begin{array}{l}\hat{\mathbf{x}}_{\mathrm{F}} \\ \hat{\mathbf{x}}_{\mathrm{B}} \\ \hat{\mathbf{x}}_{\mathrm{N}}\end{array}\right]$ 
$\left[\begin{array}{ccc}\mathbf{Q}_{\mathrm{FF}}^{\mathbf{j}} & \mathbf{Q}_{\mathrm{FB}}^{\mathbf{j}} & \mathbf{Q}_{\mathrm{FN}}^{\mathbf{j}} \\ \mathbf{Q}_{\mathrm{BF}}^{\mathbf{j}} & \mathbf{Q}_{\mathrm{BB}}^{\mathbf{j}} & \mathbf{Q}_{\mathrm{BN}}^{\mathbf{j}} \\ \mathbf{Q}_{\mathrm{NF}}^{\mathbf{j}} & \mathbf{Q}_{\mathrm{BN}}^{\mathbf{j}} & \mathbf{Q}_{\mathrm{NN}}^{\mathbf{j}}\end{array}\right]=\mathbf{S}_{\mathbf{j}}\left[\begin{array}{lll}\mathbf{Q}_{\mathrm{FF}} & \mathbf{Q}_{\mathrm{FB}} & \mathbf{Q}_{\mathrm{FN}} \\ \mathbf{Q}_{\mathrm{BF}} & \mathbf{Q}_{\mathrm{BB}} & \mathbf{Q}_{\mathrm{BN}} \\ \mathbf{Q}_{\mathrm{NF}} & \mathbf{Q}_{\mathrm{BN}} & \mathbf{Q}_{\mathrm{NN}}\end{array}\right] \mathbf{S}_{\mathbf{j}}^{\mathbf{T}}$

Aynı dönüşümler ikinci periyot ölçüleri için de uygulanmaktadır. Dönüşümler gerçekleştirildikten sonra, hareketsiz kaldıkları varsayılan noktalara ilişkin sıfır hipotezi,

$H_{0}: E\left(\hat{\mathbf{x}}_{\mathbf{F} 1}^{\mathbf{j}}\right)=E\left(\hat{\mathbf{x}}_{\mathbf{F} 2}^{\mathbf{j}}\right)$

koordinat fark vektörü,

$\mathbf{d}_{\mathbf{F}}=\hat{\mathbf{x}}_{\mathbf{F} 2}^{\mathrm{j}}-\hat{\mathbf{x}}_{\mathbf{F} 1}^{\mathrm{j}}$

fark vektörünün ağırlık katsayılar matrisi,

$\mathbf{Q}_{\mathrm{FF}}=\mathbf{Q}_{\mathrm{FF} 1}^{\mathrm{j}}+\mathbf{Q}_{\mathrm{FF} 2}^{\mathrm{j}}$

biçiminde hesaplanır. Burada, 1 alt indisi birinci periyodu, 2 alt indisi ikinci periyodu ifade eder. Sifır hipotezinin dengeleme modeline etkisi olan R büyüklüğü (28) eşitliği ile hesaplanır:

$R_{F}=\mathbf{d}_{\mathbf{F}}^{\mathbf{T}} \mathbf{Q}_{\mathbf{F F}}^{+} \mathbf{d}_{\mathbf{F}}$

Ağdaki eşlenik tüm noktalar sırasıyla birer birer datum tanımından çıkarılarak $\hat{\mathbf{x}}_{\mathbf{B}}$ ve $\mathbf{Q}_{\mathbf{B B}}$ alt vektör ve matrislerini oluştururlar. Her tanımlanan yeni datum için $R_{F}$ büyüklüğü tekrar hesaplanır. Buna göre, $R_{F}$ değerinin minimum olduğu noktanın yer değiştirmiş olduğu sonucuna varılır. Minimum $R_{F}$ değeri ile yeniden global test yapılır. Eğer test hala başka hareketli noktaların bulunduğu sonucuna götürüyorsa, hareket ettiği saptanan nokta, eşlenik olmayan noktalar ( $\hat{\mathbf{x}}_{\mathbf{N}}$ vektörü) kümesi içerisine atılır ve yerelleştirme işlemine, global uyumluluk testinde konumu değişen başka nokta olmadığı bulunana kadar devam edilir (Niemeier, 1985).

\section{Robust Yöntemlere Dayalı Deformasyon Analizi}

Caspary ve Borutta (1987) robust yöntemlerin deformasyon analizinde uygulanabilmesi amacıyla her iki periyodu ayrı ayrı serbest dengeledikten sonra aşağıdaki deformasyon analiz modelini ortaya koymuştur:

$\hat{\mathbf{x}}_{2}-\hat{\mathbf{x}}_{1}=\Delta=\mathbf{H t}+\boldsymbol{\delta}, E(\Delta)=\mathbf{H t}$

Burada, $\hat{\mathbf{x}}_{\mathbf{1}}$ ve $\hat{\mathbf{x}}_{\mathbf{2}}$ sırasıyla birinci ve ikinci periyot için kestirilen koordinat değerlerini, $\mathbf{H}$ tasarım matrisini, $\mathbf{t}$ deformasyon model parametreleri vektörünü, $\boldsymbol{\delta}$ düzeltmeler vektörünü, $\Delta$ yer değiştirme vektörünü ve $\mathrm{E}($ ) beklenen değeri ifade etmektedir. $\mathrm{Bu}$ yaklaşımda $\hat{\mathbf{x}}_{1}$ ve $\hat{\mathbf{x}}_{2}$ koordinat vektörlerinin varyans kovaryans matrisleri göz ardı edilmektedir.

İncelenen bölgede oluşacak deformasyon hakkında herhangi bir ön bilgi yoksa noktaların tek tek incelendiği yer değiştirme modeli uygulanır. Bu durumda her iki periyodu içerecek şekilde benzerlik dönüşümü uygulanarak global uyumluluk testi uygulanmaksızın yer değiştirmiş noktalar belirlenmeye çalışılır. Bu durumda (29) eşitliğinde t deformasyon model parametreler vektörü; $t_{x}$, x ekseni yönündeki öteleme; $t_{y}$, y ekseni yönündeki öteleme, $\theta$ eksenlerdeki dönüklük ve $k_{\mathrm{s}}$ ölçek çarpanından oluşmaktadır. Tasarım matrisi $\mathbf{H}$ her iki periyotta da eşlenik tüm noktalar için yazılırsa: 
$\mathbf{H}=\left[\begin{array}{cccc}1 & 0 & -\Delta y_{1} & \Delta x_{1} \\ 0 & 1 & \Delta x_{1} & \Delta y_{1} \\ 1 & 0 & -\Delta y_{2} & \Delta x_{2} \\ \vdots & \vdots & \vdots & \vdots \\ 1 & 0 & -\Delta y_{p} & \Delta x_{p} \\ 0 & 1 & \Delta x_{p} & \Delta y_{p}\end{array}\right]$

$\Delta x_{i}=x_{i}-x_{s}$

$\Delta y_{i}=y_{i}-y_{s}$

$x_{s}=\sum x_{i} / p$

$y_{s}=\sum y_{i} / p, i=1, \ldots, p$.

$\mathbf{t}=\left[\begin{array}{llll}t_{x} & t_{y} & k_{s} & \theta\end{array}\right]^{T}$

şeklinde ifade edilir. Burada, $p$ her iki periyotta da eşlenik nokta sayısını ifade etmektedir. EKK kestirimi (29) eşitliğine uygulanarak matematik modelin doğru olduğu durumlarda minimum varyans koşulunu sağlayan çözüm gerçekleştirilebilir. Fakat, modelden sapmalar meydana geldiği durumda elde edilen çözüm optimum olmaktan uzaklaşacaktır. Bu durumda oluşacak hata, kestirilen parametrelere ve tüm düzeltmelere yayılacaktır. EKK kestiriminin bu olumsuzluğu robust kestirim yöntemleri uygulanarak giderilebilmektedir. Bu çalışmada yinelemeli yeniden ağırlıklandırmalı M-kestiriciler kullanılmıştır.

Gauss-Markoff modelinde M-kestiriminin normal denklemleri;

$\frac{1}{\sigma^{2}} \sum_{i=1}^{n} \mathbf{w}\left(v_{i}\right) \mathbf{v}_{\mathbf{i}} \mathbf{a}_{\mathbf{i j}}=0, j=1,2, \ldots, u ; i=1,2, \ldots, m$

veya matris gösterimiyle,

$A^{T} W_{k} v=A^{T} W_{k}(A x-1)=0$

biçimindedir. Burada, $\mathbf{W}_{\mathbf{k}}$ düzeltmelere bağlı olarak seçilmiş bir ağırlık fonksiyonundan elde edilen köşegen bir matris ve $k$ yineleme sayısıdır. Normal denklemlerde bilinmeyen parametrelerin yanı sıra düzeltmeler de bilinmemektedir. Bu nedenle denklem sistemi ancak yineleme ile çözülebilir. Genellikle yinelemeli, yeniden ağırlıklandırmalı EKK çözümü tercih edilir (Koch, 1999). Çalışmada kullanılan yöntemlere ilişkin ağırlık fonksiyonları aşağıda verilmektedir:

Huber ağırlık fonksiyonu (Huber, 1981):

$W\left(v_{i}\right)= \begin{cases}1 & \left|v_{i}\right| \leq c \\ \frac{c}{\left|v_{i}\right|} & \left|v_{i}\right|>c\end{cases}$

Burada, $c$ sabiti için $1.5 s_{0}$ seçilmiştir.

Danimarka ağırlık fonksiyonu (Krarup, 1980):

$W\left(v_{i}\right)=\left\{\begin{array}{cc}1 & \left|v_{i}\right|<c \\ \exp \left(-\frac{\left|v_{i}\right|}{c}\right) & \left|v_{i}\right| \geq c\end{array}\right.$ 
Burada, $c$ sabiti için $1.5 s_{0}$ seçilmiştir.

Hampel ağırlık fonksiyonu (Hampel vd., 1986):

$W\left(v_{i}\right)=\left\{\begin{array}{cc}1 & 0<\left|v_{i}\right| \leq a \\ \frac{a}{\left|v_{i}\right|} & a<\left|v_{i}\right| \leq b \\ \frac{a\left(c-\left|v_{i}\right|\right)}{\left|v_{i}\right|(c-b)} & b<\left|v_{i}\right| \leq c \\ 0 & \left|v_{i}\right|>c\end{array}\right.$

Burada, $a=1.5 s_{0}, b=3 s_{0}$ ve $c=6 s_{0}$ seçilmiştir.

Andrews ağırlık fonksiyonu (Andrews, 1974):

$W\left(v_{i}\right)=\left\{\begin{array}{cc}\left(\frac{\left|v_{i}\right|}{c}\right)^{-1} \sin \left(\frac{\left|v_{i}\right|}{c}\right) & \left|v_{i}\right| \leq c \pi \\ 0 & \left|v_{i}\right|>c \pi\end{array}\right.$

Burada, $c$ sabiti için $2 s_{0}$ seçilmiştir.

Beaton ve Tukey ağırlık fonksiyonu (Beaton \& Tukey, 1974):

$W\left(v_{i}\right)=\left\{\begin{array}{cc}\left(1-\left(\frac{\left|v_{i}\right|}{c}\right)^{2}\right)^{2} & \left|v_{i}\right| \leq c \pi \\ 0 & \left|v_{i}\right|>c \pi\end{array}\right.$

Burada, $c$ sabiti için $2 s_{0}$ seçilmiştir. Ağırlık fonksiyonlarındaki $s_{0}$ değeri benzerlik dönüşümü modelinde ilk dengelemeden elde edilen değerdir.

$\mathrm{Bu}$ çalışmada robust yöntemlerin uygulanması sonucunda hangi noktaların yer değiştirdiğini belirlemek amacıyla iki farklı yaklaşım uygulanmıştır. Robust kestirimde EKK kestiriminden farklı olarak ölçüler ile kestirilen parametreler arasındaki ilişki doğrusal değildir ve varyans yayılma kuralı doğrudan uygulanamaz. Fakat anlamlılık testi için bilinmeyen parametrelerin $\mathbf{C}_{\mathbf{t t}}$ ve düzeltmelerin $\mathbf{C}_{\boldsymbol{\delta} \boldsymbol{\delta}}$ varyans-kovaryans matrislerinin bilinmesi gerekir. Birinci yaklaşımda nokta yer değiştirmelerinin belirlenebilmesi için düzeltmelere anlamlılık testi uygulanmıştır. Birinci yaklaşıma göre sıfır hipotezi tüm eşlenik noktalar için aşağıdaki şekilde tekrarlanır:

$H_{0}: E\left(\boldsymbol{\delta}_{\mathbf{i}}\right)=\mathbf{0}$

$H_{1}: E\left(\boldsymbol{\delta}_{\mathbf{i}}\right)>\mathbf{0}$

Burada $i$ dizini eşlenik bir noktayı belirtir. Sıfır hipotezine ilişkin test istatistiği,

$T_{i}=\boldsymbol{\delta}_{i}^{T} \mathbf{C}_{\delta i \delta i}^{-1} \boldsymbol{\delta}_{i} \sim \chi_{2,1-\alpha}^{2}$

şeklindedir (Koch, 1999). Her bir eşlenik nokta için test istatistik değeri $\chi_{2,1-\alpha}^{2}$ sınır değeri ile karşılaştırılır. Sınır değeri aşan noktalar yer değiştirmiş olarak kabul edilir. Robust kestirim sonucunda test işlemlerinin yapılabilmesi amacıyla $\mathbf{C}_{\boldsymbol{\delta} \delta}$ değerleri, EKK kestiriminden elde edilmiştir. Bu çalışmada $\alpha=0.05$ alınmıştır. Üç boyutlu durumda (40) eşitliğindeki $\chi_{2,1-\alpha}^{2}, \chi_{3,1-\alpha}^{2}$ olur. 
İkinci yaklaşımda, robust uyuşumsuz ölçü analizinde olduğu gibi dönüşümden elde edilen düzeltme değerleri $3 M A D$ (Median Absolute Deviation) sınır değeri ile karşılaştırılmıştır (Rousseeuw \& Leroy, 1987). Düzeltme değeri, sınır değeri geçen nokta yer değiştirmiş olarak kabul edilmiştir.

\section{Uygulama}

Jeodezik ağlarda deformasyon analizine ait sonuçların güvenilirliğinin araştırılması kapsamında yer değiştirmiş noktaların gerçekte hangi noktalar olduğunun bilinmesi gerekir. Normalde hangi noktaların yer değiştirdiği analizden önce bilinmez. Bu nedenle güvenilirliğin araştırılması amacıyla simülasyon yapılması gerekmektedir. Çünkü gerçekte olan durum ile analiz sonucunda ortaya çıkan durumun karşılaştırılması gerekir. Bu bağlamda çalışmada gerçek veri seti kullanılmamıştır. Çalışmada analizler gerçekleştirilirken, noktaların hangisinde yer değiştirme olduğuna dair herhangi bir önsel bilgi sistemde bulunmamaktadır. Bu durum da aslında deformasyon analiz modeli açısından gerçeğe yakınlık göstermektedir. Ayrıca, simülasyondan gerçekçi sonuçların elde edilmesi için uygun yer değiştirme büyüklüklerinin belirlenmesi gerekir.

\subsection{Yatay Kontrol Ağında Ölçülerin Elde Edilmesi}

İki boyutlu ağlarda ve üç boyutlu ağlarda simülasyon çalışmalarında yer değiştirme büyüklüğünün belirlenmesi Hekimoğlu vd. (2010) ve Durdağ, Hekimoğlu ve Erdoğan (2018) yayınlarında ortaya konmuştur. Bu çalışmada, 9 nokta ve 54 ölçüden (36 adet doğrultu ve 18 adet kenar ölçüsü) oluşan Şekil 1'de verilen yatay kontrol ağı kullanılmıştır. Ağda tüm doğrultu ve kenar ölçümlerinin yapıldığı kabul edilmiştir. Kenar ölçümleri 415 m ile 970 m arasında değişmektedir.

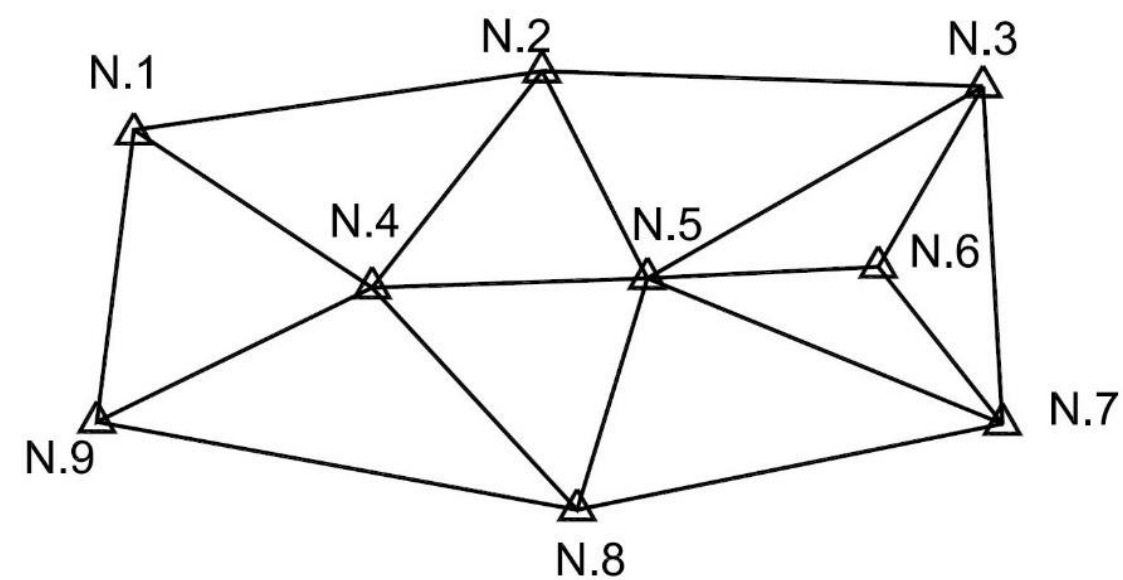

Şekil 1: Uygulamada kullanılan yatay kontrol ağı

Bu ağa ilişkin iki periyot ölçümler aşağıdaki adımlar kullanılarak simüle edilmiştir:

1. Adım: Ăğda öncelikle nokta koordinatları bilgisayar çizim programında belirlenmiştir. Bu nokta koordinatlarından rastgele hata ve kaba hata içermeyen doğrultu ve kenar ölçüleri (hatasız ölçüler) $\mathbf{l}$ ikinci jeodezik temel ödev hesaplamaları ile elde edilmiştir.

2. Adım: Deformasyon analizinde kullanılacak ölçüleri oluşturmak için her periyot için farklı rastgele hatalar vektörü (e) hatasız ölçüler vektörüne eklenmiştir. Birinci periyot ölçüleri oluşturulurken, hatasız ölçülere sadece rastgele hatalar ( $\left.\mathbf{e}_{\mathbf{1}}\right)$ eklenmiştir. İkinci periyot ölçülerinde ise hem rastgele hatalar (ê2) hem de noktalara ilişkin yer değiştirmeler eklenmiştir. Birinci ve ikinci periyot ölçüleri, 
$\mathbf{l}_{\mathbf{1}}=\overline{\mathbf{l}}+\mathbf{e}_{1}$

$\mathbf{l}_{2}=\overline{\mathbf{l}}+\mathbf{e}_{2}+\mathbf{A z}$

şeklinde oluşturulmuştur. Burada, e $\mathbf{1}$ ve $\mathbf{e}_{2}$ normal dağılımlı rastgele hata vektörleri, A katsayılar matrisi ve $\mathbf{z}$ yatay deformasyon vektörüdür:

$\mathbf{z}=\left[\begin{array}{lllllll}Z_{1 x} & z_{1 y} & z_{2 x} & Z_{2 y} & \ldots & z_{u x} & z_{u y}\end{array}\right]$

3. Adım: Birinci ve ikinci periyot ölçüleri birlikte (yani $\mathbf{l}_{\mathbf{1}}, \mathbf{l}_{2}$ ) bir örnek küme oluşturur. Bu şekilde 10000 farklı örnek küme oluşturulmuş ve analizler gerçekleştirilmiştir. Yatay kontrol ağlarında deformasyon iki bileşene sahiptir. $\mathbf{z}$ deformasyon vektörünün $z_{x}$ bileşeni deformasyonun x ekseni üzerindeki iz düşümünü, $z_{y}$ bileşeni de y ekseni üzerindeki iz düşümünü ifade etmektedir. İkinci periyot ölçüleri oluşturulurken $\mathbf{z}$ vektöründe sadece deformasyon eklenecek noktalara ilişkin bileşenler “ 0 ” dan farklidir.

Rastgele hata vektörü MATLAB programının rastgele normal dağılım hata üreticisi kullanılarak birinci ve ikinci periyot için ayrı ayrı farklı normal dağılımlardan $N(\mu=0, \sigma)$ üretilmiştir. Doğrultu ölçüleri için $\sigma_{d}= \pm 0.2$ mgon, kenar ölçüleri için $\sigma_{s}= \pm(3+2 p p m)$ mm öngörülmüştür. (41) ve (42) eşitlikleriyle $\mathbf{l}_{\mathbf{1}}$ ve $\mathbf{l}_{\mathbf{2}}$ ölçü vektörleri oluşturulmuştur. Her iki periyotta ağın geometrisi aynı olduğu için periyotlara ilişkin ağırlık matrisleri birbirine eşittir. Doğrultu kenar ağında ağırlık matrisi,

$\mathbf{P}=\left[\begin{array}{cc}\mathbf{P}_{\mathbf{d}} & \mathbf{0} \\ \mathbf{0} & \mathbf{P}_{\mathbf{s}}\end{array}\right]$

biçimindedir.

$\mathbf{P}_{\mathbf{d}}=\operatorname{diag}\left(\sigma_{0}^{2} / \sigma_{d 1}^{2}, \sigma_{0}^{2} / \sigma_{d 2}^{2}, \ldots, \sigma_{0}^{2} / \sigma_{d m 1}^{2}\right)($ doğrultu ölçüleri)

$\mathbf{P}_{\mathbf{s}}=\operatorname{diag}\left(\sigma_{0}^{2} / \sigma_{s 1}^{2}, \sigma_{0}^{2} / \sigma_{s 2}^{2}, \ldots, \sigma_{0}^{2} / \sigma_{s m 2}^{2}\right)($ kenar ölçüleri)

$\sigma_{0}^{2}$ birim ağırlıklı varyans ve 0.04 mgon² olarak seçilmiştir. $m_{1}$ doğrultu ölçülerinin sayısını, $m_{2}$ kenar ölçülerinin sayısını ifade etmektedir.

z vektörünün elemanları hesaplanırken, Hekimoğlu vd. (2010) tarafından nasıl elde edildiği anlatılan karşılaştırma çemberi kullanılmıştır. Bu çemberin elemanları ağdaki 9 noktaya göre hesaplanmış ve yarıçapı $r=6.9$ mm olarak elde edilmiştir.

\subsection{Analizler}

Robust yöntemler kullanılarak gerçekleştirilen deformasyon analizinin güvenilirliğinin araştırılması amacıyla ölçülerin ve deformasyon büyüklüklerinin simüle edildiği Şekil 1'de verilen yatay kontrol ağında Ortalama Başarı Oranı (OBO) değerleri hesaplanmıştır. OBO ilk olarak uyuşumsuz ölçü araştırmasında, yöntemlerin etkinliklerinin karşılaştırılması için kullanılmıştır (Hekimoğlu \& Koch, 1999). Bu kavram deformasyon analizi çalışmalarında nivelman ağlarında, doğrultu kenar ağlarında ve GPS ağlarında uygulanmıştır (Hekimoğlu, Demirel \& Aydın, 2002; Hekimoğlu vd., 2010; Durdağ vd., 2018). Bu çalışmada da OBO kavramı, yatay kontrol ağında robust yöntemler kullanılarak gerçekleştirilen deformasyon analizinin güvenilirliğinin araştırılmasında kullanılmıştır.

Birinci ve ikinci periyot ölçüleri simülasyonla oluşturulan ağda, bu iki ölçüm periyodu birlikte bir örnek kümeyi oluşturmaktadır. Analiz sonucunda, yöntemin deformasyona uğramış olarak bulduğu noktalar, ikinci periyot ölçüleri 
oluşturulurken yer değiştirmelerin eklendiği noktalar ise, yöntem başarılı olarak kabul edilmektedir. Aksi takdirde başarısız sayılmaktadır. Kısaca, hangi noktalarda yer değiştirme üretilmişse ve deformasyon analizi de aynı noktaları belirlemişse yöntem başarılı sayılmaktadır.

Birinci periyot ölçümlerinin oluşturulabilmesi için birinci periyoda ait ê rastgele hata vektörü üretilmiş olsun. Öngörülen belirli sayıdaki yer değiştirmiş nokta sayısı için, yeni bir ikinci periyoda ait e 2 rastgele hata vektörü üretilerek, yer değiştirmenin eklendiği nokta ve yer değiştirmenin büyüklüğü rastgele değiştirilerek çok sayıda örnek küme oluşturulabilir. Başarı oranı (BO) bu örnek kümelerden başarılı deney sayısının toplam deney sayısına bölümü ile elde edilir:

$\gamma_{i}\left(L, \mathrm{l}_{1 \mathrm{i}}, \mathrm{l}_{2 \mathrm{j}}\right.$, int $\left., n_{d}, e_{1 i}, \mathrm{e}_{2 \mathrm{j}}, m, u\right)=\frac{q_{i j}}{N}$

Burada, L kullanılan analiz yöntemini, int yer değiştirmenin aralığını, $l_{l i}$ birinci periyot, $l_{2 j}$ ikinci periyot ölçülerini, $n_{d}$ yer değiştiren nokta sayısını, $m$ ölçü sayısını, $q_{i j}$ yer değiştiren noktaların doğru belirlendiği örnek küme sayısını, $u$ bilinmeyen sayısını ve $N$ toplam örnek küme sayısını ifade etmektedir.

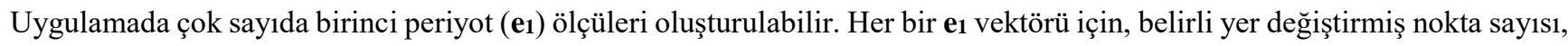
deformasyon analiz yöntemi ve yer değiştirme büyüklüğünde BO hesaplanabilir. Bu başarı oranlarının ortalaması, OBO olarak adlandirılir ve

$\gamma_{\text {ort }}\left(L\right.$, int $\left., n_{d}, n, u\right)=\frac{\sum_{i=1}^{k} \gamma_{i}\left(L, l_{1 i}, l_{2 j}, i n t, n_{d}, e_{1 i}, n, u\right)}{k}$

biçiminde ifade edilir. Burada k, $\mathbf{e}_{1}$ rastgele hata vektörü oluşturma sayısıdır. Böylece, değişik etkiler (deformasyon analiz yöntemi, nokta sayısı, yer değiştirme büyüklük aralığı) göz önüne alınarak OBO hesaplanabilir.

$\mathrm{Bu}$ çalışmada yöntemlerin OBO değerlerinin hesaplanması için yer değiştirmeler her bir senaryo için ağdaki herhangi bir noktaya rastgele eklenmiştir. OBO değerleri $(r, 2 r),(r, 3 r)$ ve $(2 r, 3 r)$ aralıklarında farklı sayıdaki yer değiştirmiş nokta için elde edilmiştir. Analizlerde iki farklı model kullanılmıştır. Birinci modelde benzerlik dönüşümünden elde edilen düzeltmeler (40) nolu eşitlikte verilen test büyüklüğü kullanılarak test edilmiştir. İkinci yaklaşımda ise robust uyuşumsuz ölçü analizinde olduğu gibi dönüşümden elde edilen düzeltme değerleri 3MAD sınır değeri ile karşılaştırılmıştır. Düzeltme değeri sınır değerini geçen nokta yer değiştirmiş olarak kabul edilmiştir. Birinci yaklaşıma ait farklı yer değiştiren nokta sayılarına (YDNS) göre OBO değerleri Şekil 2, 3 ve 4'de verilmektedir. Aynı senaryolar için ikinci yaklaşıma ait sonuçlar Şekil 5, 6 ve 7'de gösterilmektedir. 


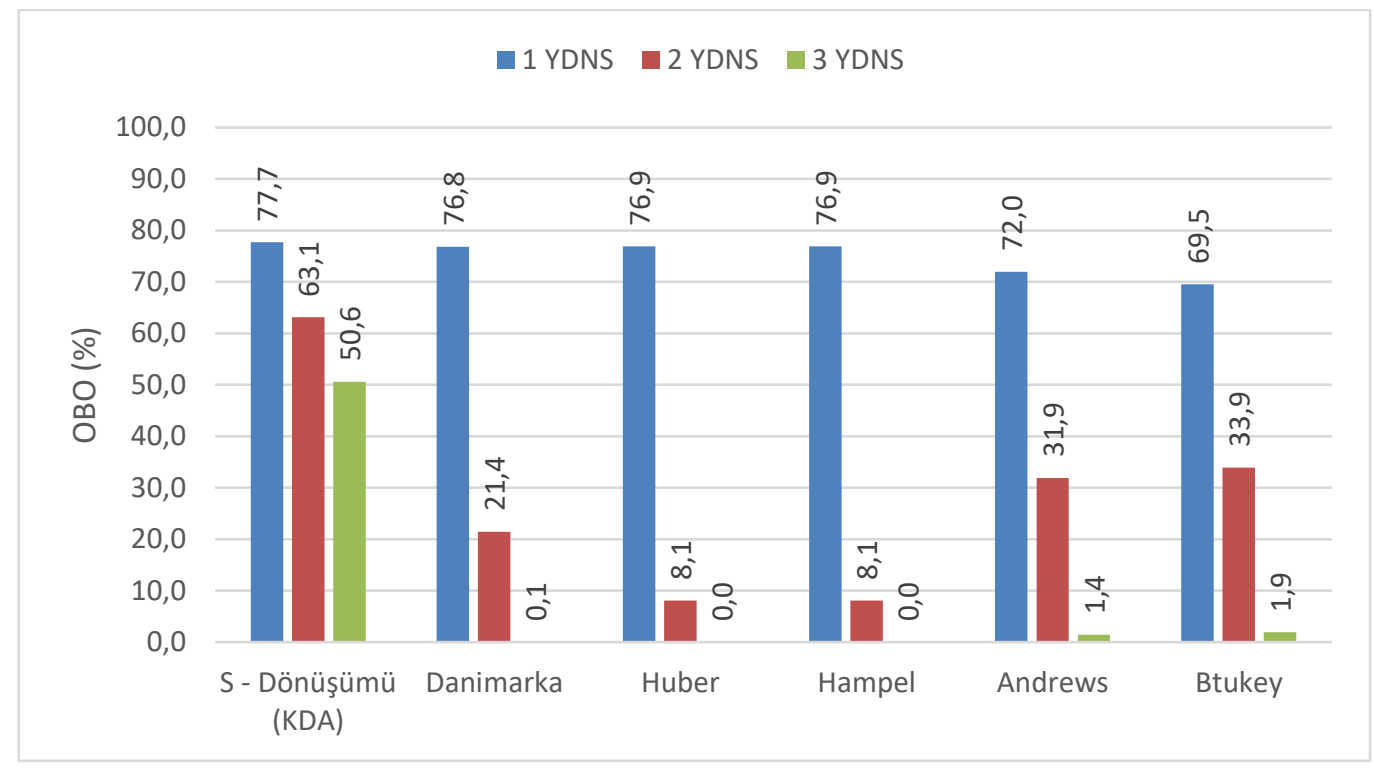

Şekil 2: KDA ve birinci yaklaşımda robust yöntemlerin OBO değerleri $(r, 2 r)$

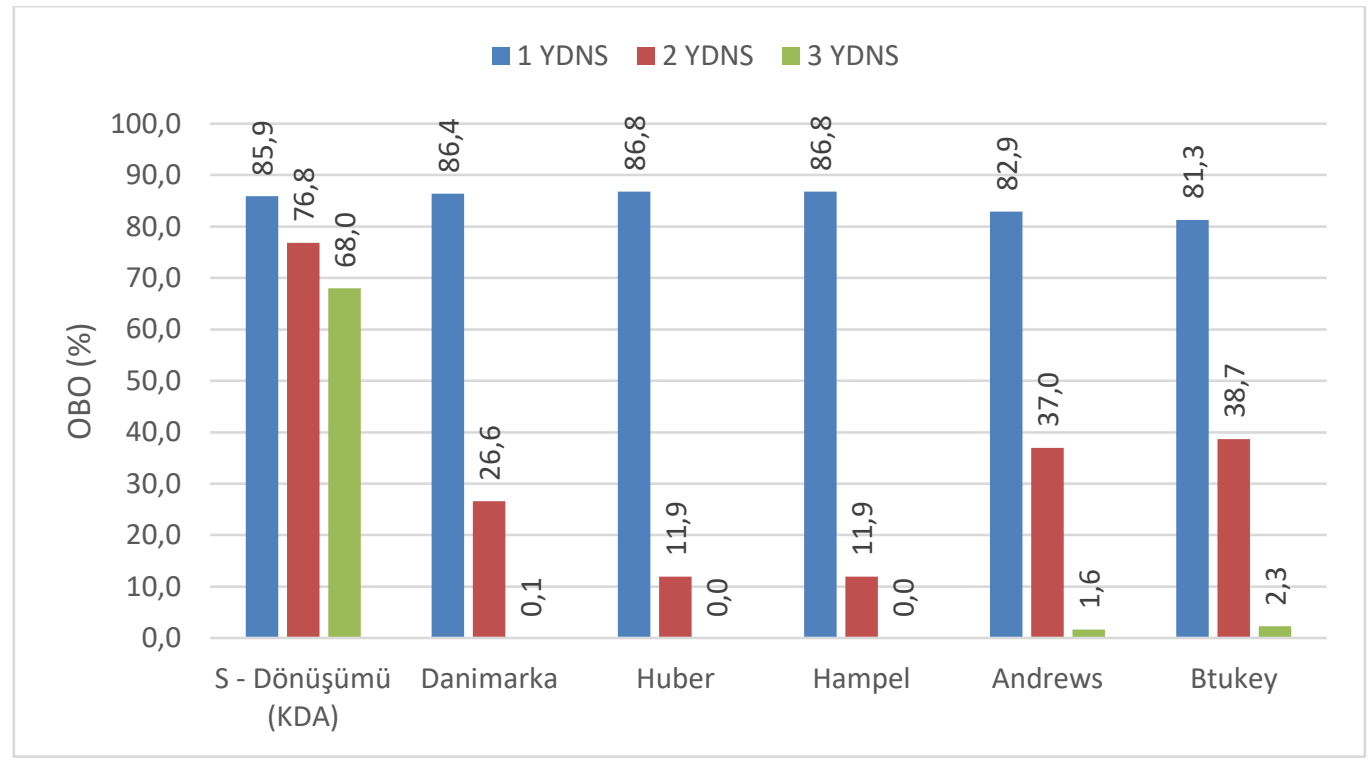

Şekil 3: KDA ve birinci yaklaşımda robust yöntemlerin OBO değerleri (r, 3r) 


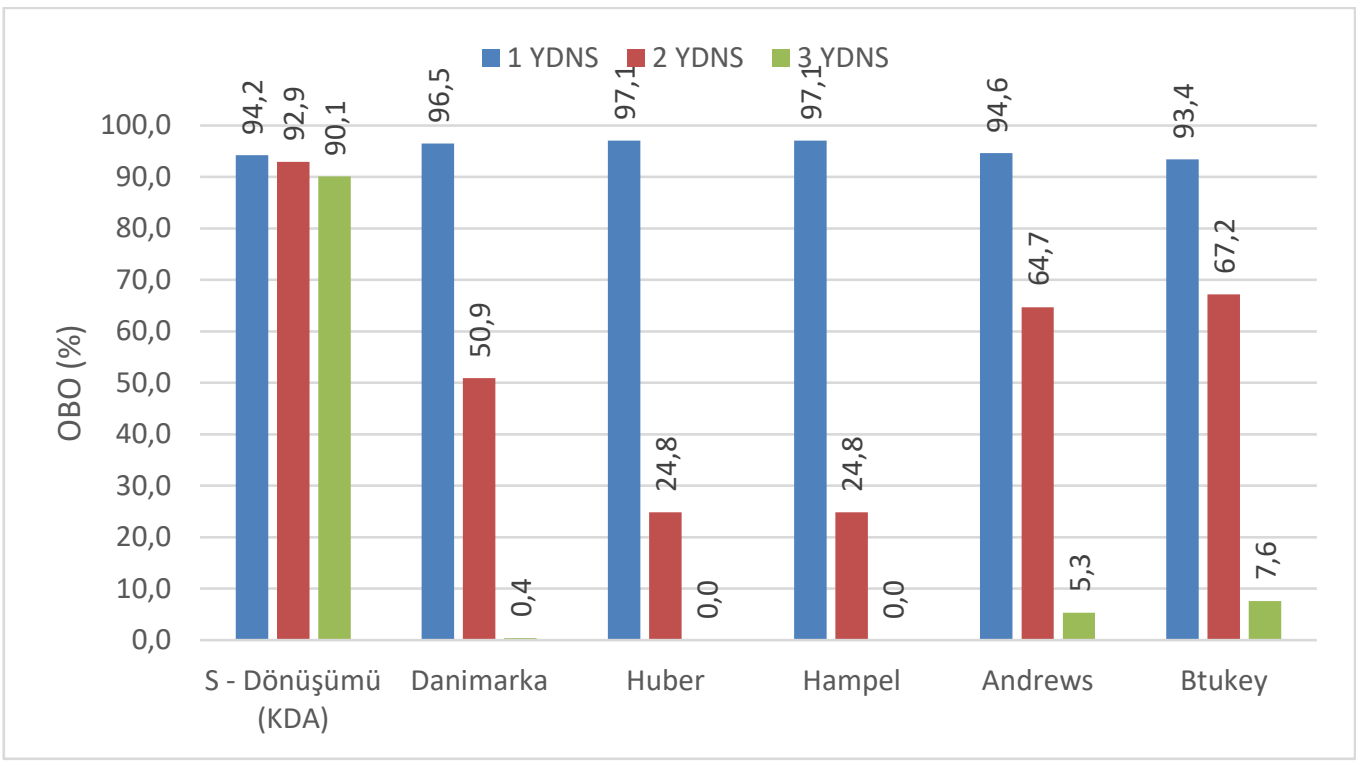

Şekil 4: KDA ve birinci yaklaşımda robust yöntemlerin OBO değerleri $(2 r, 3 r)$

Şekil 2, 3 ve 4 incelendiğinde en başarılı sonuçlar KDA uygulandığında elde edilmiştir. Yöntemlerin OBO değerleri ağda YDNS bire eşit olduğunda yüksek ve birbirine yakın çıkmasına rağmen; ağda YDNS arttıkça birinci yaklaşımda uygulanan robust yöntemlerin güvenilirlikleri hızlı bir şekilde düşmektedir. Yer değiştirmenin büyüklüğü arttığında yöntemlerin başarı oranları da artmaktadır. Özellikle büyük genlikli yer değiştirmeler olduğu durumda KDA'nın sonuçları \%90'ın üzerindedir. İkinci yaklaşımda robust yöntemlerden elde edilen sonuçlar incelendiğinde en güvenilir sonuçların birinci yaklaşımda olduğu gibi KDA’ya ait olduğu görülmektedir.

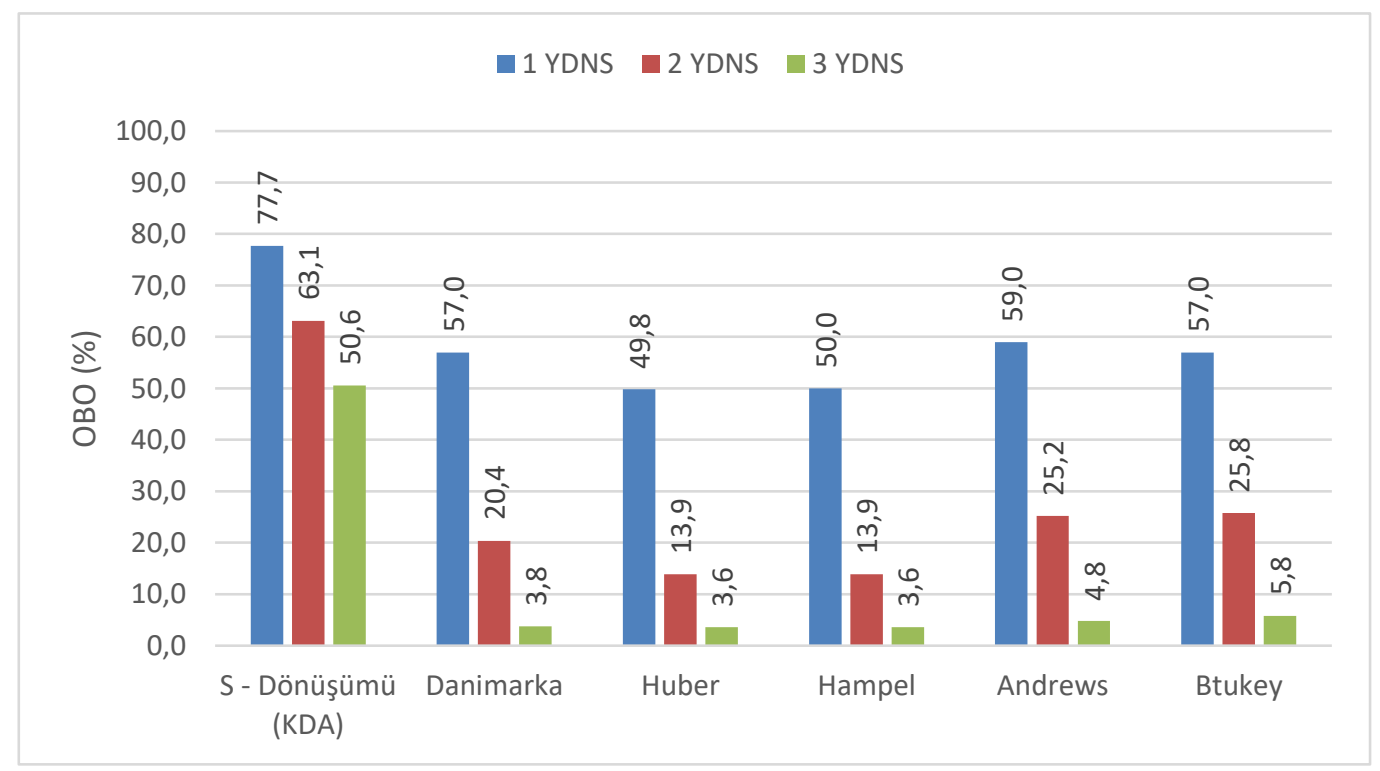

Şekil 5: KDA ve ikinci yaklaşımda robust yöntemlerin $O B O$ değerleri $(r, 2 r)$ 


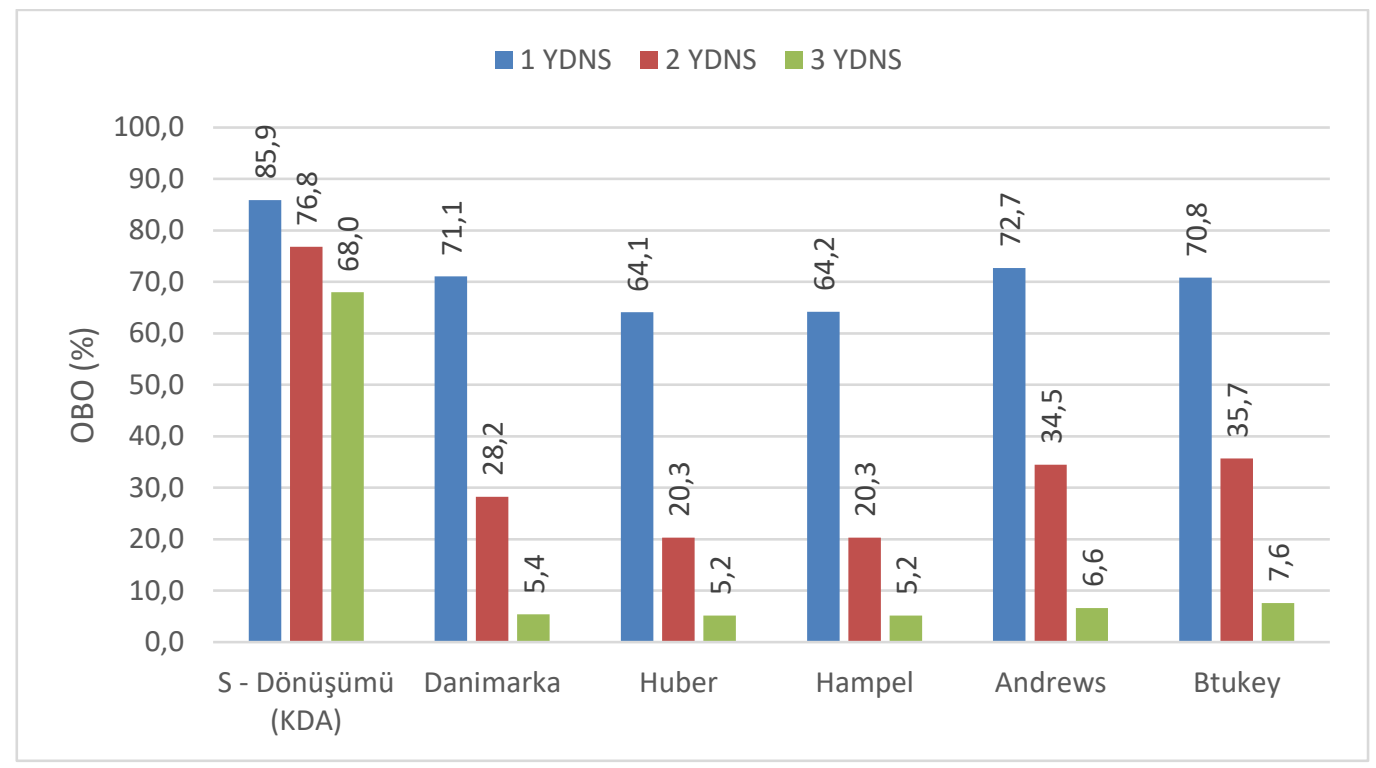

Şekil 6: KDA ve ikinci yaklaşımda robust yöntemlerin OBO değerleri $(r, 3 r)$

Birinci ve ikinci yaklaşımda robust yöntemler karşılaştırıldığında birinci yaklaşımın daha güvenilir sonuçlar verdiği görülmektedir. Özellikle küçük genlikli yer değişstirmeler için ikinci yaklaşımın başarısız olduğu görülmektedir.

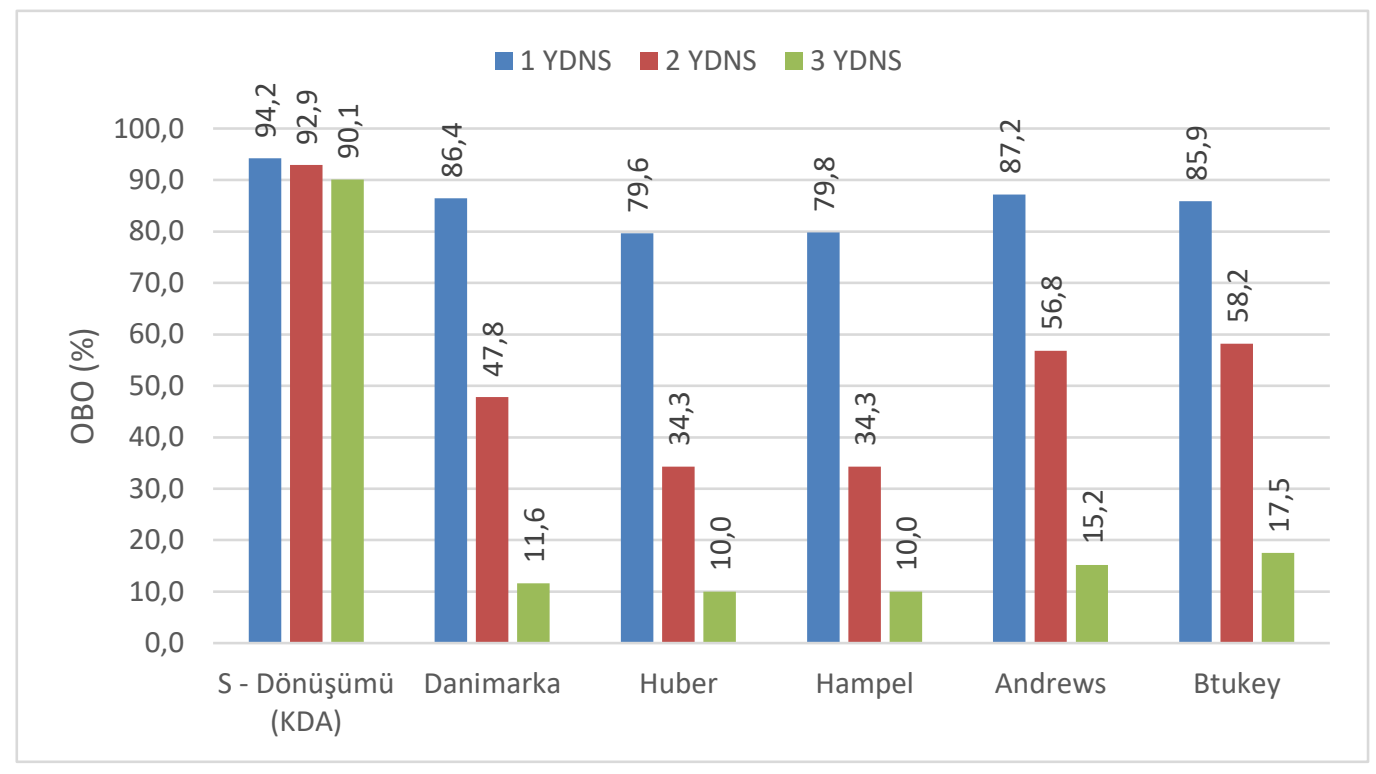

Şekil 7: KDA ve ikinci yaklaşımda robust yöntemlerin OBO değerleri (2r, 3r)

\section{Sonuçlar}

$\mathrm{Bu}$ çalışmada robust yöntemlerin deformasyon analizinde uygulanması durumunda elde edilen sonuçların güvenilirliği araştırılmıştır. Gerçekleştirilen simülasyon çalışmasında robust yöntemler iki farklı yaklaşımla deformasyon analizine uygulanmıştır. Birinci yaklaşımda benzerlik dönüşüm modelinden hesaplanan düzeltme değerlerine anlamlıllk testi uygulanmıştır. İkinci yaklaşım olarak benzerlik dönüşümü modeline robust yöntemler uygulandığında, elde edilen düzeltmeler $3 M A D$ sınır değeri ile karşılaş̧ırılarak yer değiştiren noktaların yakalanması amaçlanmıştır. Birinci yaklaşım sonuçlarına göre ağda yer değiştiren bir nokta olması durumunda KDA’ya benzer sonuçların elde edildiği görülmektedir. Buna karşın, ağdaki yer değiştiren nokta sayısı arttıkça birinci yaklaşım robust çözümleri ile KDA çözümleri farklılık göstermektedir. İkinci yaklaşımda da birinci yaklaşımda olduğu gibi ağdaki yer değiştiren nokta sayısı arttıkça robust 
yöntemlerin OBO değerlerinde hızlı bir düşüş görülmektedir. Ayrıca, ikinci yaklaşımda ağda yer değiştiren bir nokta olması durumunda da sonuçların güvenilirliği hem birinci yaklaşımdan hem de KDA'dan daha düşüktür.

Analizlerde dikkate alınan tüm yöntemlerin sonuçları incelendiğinde ağdaki yer değiştiren nokta sayısı arttıkça sonuçların güvenilirlikleri düşmektedir. Buna karşın, yer değiştirme büyüklükleri arttığında sonuçların güvenilirlikleri de artmaktadır. Benzerlik dönüşüm modeli içerisinde deformasyon analizinde robust yöntemler kullanılmak istendiğinde; ağda yer değiştiren bir nokta bulunması durumunda birinci yaklaşıma göre Danimarka, Huber ve Hampel robust kestirim yöntemleri tercih edilebilir. Ağda birden çok yer değiştiren nokta bulunması durumunda ise robust yöntemlerin sonuçlarının güvenilirlikleri düşmektedir.

\section{Kaynaklar}

Andrews, D. F. (1974). A robust method for multiple linear regression. Technometrics, 16(4), 523-531.

Baarda, W. (1968). A testing procedure for use in geodetic networks. Netherlands geodetic commission, 2(5).

Beaton, A. E., \& Tukey, J. W. (1974). The fitting of power series, meaning polynomials, illustrated on band-spectroscopic data. Technometrics, 16(2), 147-185.

Caspary, W., \& Borutta, H. (1987). Robust estimation in deformation models. Survey review, 29(223), 29-45.

Demirel, H. (1987). S Transformasyonu ve Deformasyon Analizi, Türkiye 1. Bilimsel ve Teknik Kurultayl, 593, 608.

Duchnowski, R., \& Wiśniewski, Z. (2014). Comparison of two unconventional methods of estimation applied to determine network point displacement. Survey review, 46(339), 401-405.

Durdağ, U. M., Hekimoğlu, S., \& Erdoğan, B. (2018). Reliability of models in kinematic deformation analysis. Journal of surveying engineering, 144(3), 04018004.

Hampel, F. R., Ronchetti, E. M., Rousseeuw, P. J., \& Stahel, W. A. (1986). Robust statistics. New York: Wiley.

Hekimoğlu, S., \& Koch, K. R. (1999). How can reliability of the robust methods be measured. Proceedings of the Third Turkish-German Joint Geodetic Days, Istanbul, 179-196.

Hekimoğlu, S., Demirel, H., \& Aydın, C. (2002). Reliability of the conventional deformation analysis methods for vertical networks. FIG XXII International Congress, Washington.

Hekimoğlu, S., \& Berber, M. (2003). Effectiveness of robust methods in heterogeneous linear models. Journal of geodesy, 76(11-12), 706713.

Hekimoğlu, S. (2005). Do robust methods identify outliers more reliably than conventional test for outlier. Zeitschrift für Vermessungwesen, 3, 174-180.

Hekimoğlu, S., \& Erenoğlu, R. C. (2007). Effect of heteroscedasticity and heterogeneousness on outlier detection for geodetic networks. Journal of Geodesy, 81(2), 137-148.

Hekimoğlu, S., Erdoğan, B., \& Butterworth, S. (2010). Increasing the efficacy of the conventional deformation analysis methods: alternative strategy. Journal of Surveying Engineering, 136(2), 53-62.

Huber P. J. (1981). Robust statistics, New York: Wiley.

Koch, K. R. (1985). Ein statistisches auswerteverfahren für deformationsmessungen. Allgemeine Vermessungs-Nachrichten, 92(3), 97-108.

Koch, K. R. (1999). Parameter estimation and hypothesis testing in linear models. Springer Science \& Business Media.

Krarup, T. (1980). Gotterdammerung over least squares adjustment. In Proc. 14th Congress of the International Society of Photogrammetry (Vol. 3, pp. 369-378).

Niemeier W. (1985). Deformations analyse, in: H. Pelzer, (ed.), Geodaetische Netze in Landes - und Ingenieurvermessung II, Konrad Wittwer: Stuttgart, 559-623.

Nowel, K., \& Kamiński, W. (2014). Robust estimation of deformation from observation differences for free control networks. Journal of geodesy, 88(8), 749-764.

Nowel, K. (2016). Investigating efficacy of robust M-estimation of deformation from observation differences. Survey review, 48(346), 2130. 
Öztürk E. (1991). Doğrusal Hipotez Testleri, Harita Dergisi, 106, 1-21.

Öztürk, E., Konak, H., \& Atasoy, V. (2006). Deprem Bölgelerinde Yerkabuğu Hareketlerinin İzlenmesi. Harita Dergisi, 135, 52-63.

Pelzer H. (1971). Zur analyse geodätischer deformationsmessungen, Deutsche Geodätische Kommission, C-164, München, Germany.

Pope, A. J. (1976). The statistics of residuals and the detection of outliers (No. NOS-65-NGS-1).

Rousseeuw, P. J., \& Leroy, A. M. (1987). Robust regression and outlier detection (Vol. 1). New York: Wiley.

Welsch, W., \& Heunecke, O. (2001). Models and terminology for the analysis of geodetic monitoring observations. Official report of the ad-hoc committee of FIG working group, 6, 390-412.

Wiśniewski, Z., \& Zienkiewicz, M. H. (2016). Shift-M split* estimation in deformation analyses. Journal of surveying engineering, 142(4), 04016015.

Yu, H., Shen, Y., Yang, L., \& Nie, Y. (2017). Robust M-estimation using the equivalent weights constructed by removing the influence of an outlier on the residuals. Survey Review, 51(364), 60-69.

Zienkiewicz, M. H., Hejbudzka, K., \& Dumalski, A. (2017). Multi split functional model of geodetic observations in deformation analyses of the Olsztyn Castle. Acta Geodyn. Geomater, 14(2), 195-204. 